This is an Accepted Manuscript of an article published by Taylor \& Francis in International Journal of Social Research Methodology on 1 April 2015, available online at http//www.tand fonline.com/doi/abs/10.1080/13645579.2015.1017903

Published details:

Virginia Morrow and Gina Crivello. 2015. 'What is the value of qualitative longitudinal research with children and young people for international development', International Journal of Social Research Methodology 18 (3): 267-280.

The article is reproduced in accordance with the self-archiving policies of Taylor and Francis.

\title{
What is the value of qualitative longitudinal research with children and young people for international development?
}

Virginia Morrow and Gina Crivello, Young Lives, Department of International Development, University of Oxford

Corresponding Author: virginia.morrow@qeh.ox.ac.uk

\begin{abstract}
This paper draws on data from Young Lives, a longitudinal study of childhood poverty, to explore how international development research might be strengthened by including qualitative longitudinal research. We review three problems in development studies: a) the relatively low status of qualitative research within the hierarchy of development knowledge, b) the predominance of cross-sectional research, and, c) marginality of research with children and young people. We offer examples from Young Lives research on early marriage in Ethiopia, household poverty dynamics in India and Ethiopia, and aspirations and migration in Peru, to highlight the potential of QLR to address these drawbacks. We suggest that QLR illuminates the dynamic complexities of the processes and practices of everyday life, how they are experienced by children and young people, the responses they make, and the shifting trajectories of their lives.
\end{abstract}

\section{Introduction}

The post-2015 Sustainable Development Agenda emphasises the importance of measurement of progress, and calls for a 'data revolution for sustainable development, with a new international initiative to improve the quality of statistics and information available... to enable monitoring and accountability' (UN, 2013, p. 21). Longitudinal cohort research has much to offer, as progress towards development goals can be tracked over time. However, 
statistical analysis often leaves elements of the social world unexplored and unexplained. Qualitative longitudinal research (henceforth QLR) illuminates complexities that can be hidden by statistical trends (see Thomson \& McLeod, 2015, Thomson et al., 2014). This paper draws on Young Lives, a study of children growing up in four low- and middle-income countries during the period of the Millennium Development Goals (MDGs), to demonstrate the applicability of QLR with children and young people for international development. QLR with children and young people is limited in development studies ${ }^{1}$, though there are examples from social anthropology and social geography (see Dyson, 2014, Katz, 2004, Punch 2012, Van Blerk et al., 2014). Questions that lend themselves to QLR relate to the life course, trajectories, and critical moments, as well as the motivations and experiences of biographical change, including community dynamics, all current topics of concern in policy debates on adolescence, early marriage, child labour, quality of schooling and so on (Crivello, 2011, Morrow, 2013a). Qualitative approaches are well-suited to explore experiences, agency, priorities, definitions and interpretations. This paper contributes to the field of longitudinal research with children and young people, and is intended to be useful for other researchers, as well as practitioners and policy-makers attempting to understand dynamics and complexity relating to childhood poverty, children's agency and temporality.

The paper is structured as follows. First, we explore three 'problems' within development research, and consider what QLR can offer. Then we describe how QLR is used within Young Lives, giving examples relating to: (1) early marriage in Ethiopia to demonstrate a biographical approach; (2) household poverty dynamics in India and Ethiopia; and, 3) migration aspirations and movements across space and time in Peru. These examples enable us to explore subjectivities within cross-national approaches, illuminating the intersections between structural factors and individual lives in time.

\section{QLR within development studies}

There are three problems within international development research. First, the dominant discipline and epistemology within international development is economics. As Fourcade, Ollion and Algan (2014, p. 5) suggest, 'the theory of action that comes with economists' analytical style is hardly compatible with the basic premise of much of the human science, namely that social processes shape individual preferences (rather than the other way round)'. Qualitative research has a relatively low status within the hierarchy of development knowledge, and 'qualitative life course methodologies remain rather marginal in development 
studies and tend to lack credibility with more quantitatively-oriented researchers and public policy makers' (Locke and Lloyd-Sherlock, 2011, p. 1131). Hulme (2004) describes the growth of the field of measuring global poverty during the late 1990s, which generated statistics about millions of people in poverty, and suggests that while it is vital to 'think big' about poverty,

such grand approaches are not unproblematic. Ultimately, it is individual people who experience the deprivations of poverty, not countries or regions. Understanding what happens 'on average' or to the 'average' poor person or household can be an erroneous basis for decisions on intervention ... In addition 'big' approaches can lead to the relative neglect of micro-level actors and informal processes in analysis and action (Hulme, 2004, p. 162).

Hulme's case study of one household over time demonstrates the importance of family networks and informal civil society for poor households, and the way in which ill-health and poor services contribute to the creation and perpetuation of poverty, often overlooked in statistical surveys (Hulme, 2004, Hulme \& Moore, 2010). Some aspects of human behaviour are better explored through qualitative approaches, such as questions about social norms and values, and how these change over time and across generations, and there are indications that QLR may become more accepted in development research, especially when it is combined with quantitative research (see White and Jha, 2013) ${ }^{2}$.

Second, as Locke and Lloyd-Sherlock (2011, p. 1140) suggest, development studies tends to 'fetishize the present', or to live in the 'perpetual present' (Lewis, 2009, p. 33). Crosssectional research predominates, but perhaps this is to be expected in a subject area that is problem-oriented and seeks quick cost-effective answers (see also Fourcade et al., 2014). QLR is gaining traction in social policy research in high-income countries. McLeod and Thomson (2009, p. 62) note that QLR provides insights 'into the social and psychological processes that underpin behaviours that ... governments are increasingly interested in influencing: social responsibility, resilience, life-long processes such as education, work' ${ }^{3}$. For example, in the UK, Ridge and Millar (2011) use QLR to improve knowledge of poverty dynamics and the effects of policy on everyday lives, in light of findings from large-scale surveys indicating that lone parents find it difficult to move out of poverty. They studied working lone mothers and their children living on low-incomes, over three to four years, locating their family experience within the context of policy shifts and wider labour market forces. QLR revealed that families were vulnerable to small shocks which accumulate over time and to changes in family circumstance (such as job loss/change or marriage), making 
improving family circumstance on a low-income difficult (Ridge \& Millar, 2011, p.95). These findings extend survey research by documenting how whole families, not just individuals with jobs, manage on low-incomes, and how changing circumstances (at home, work or in policy) affect everyday lives and choices across time.

In development studies, there appears to be an increasing desire to move beyond one-off accounts (Locke \& Lloyd-Sherlock, 2011, Paerregaard, 1998, Bernays et al., forthcoming). There are challenges: QLR is expensive, and requires commitment from researchers, funders, and from study populations. But QLR may become more pertinent in future, because as already noted, the Post-2015 Sustainable Development Agenda emphasizes measurement and monitoring progress of targets, and children and youth are central to these debates (UN, 2013).

Third, research with children and young people remains marginal in international development $^{4}$, despite long-held critiques (see Ennew \& Milne, 1989). This is surprising given that several MDGs were focussed on children, and that the majority of populations in many low-income countries consists of those under 18 . There is research on children - as future human capital, focusing on early investments and later outcomes, but it involves the uncritical acceptance of constructions of childhood originating in high-income countries, especially from US developmental psychology. As Huijsmans et al. (2014, p. 163) argue,

the incorporation of the young in theories and practices of development can too often be characterised as an 'absent presence'... the young are evidently present as targets of development interventions, and often feature prominently on the covers of development reports and textbooks. Ideologies and practices of development are also frequently justified or critiqued in the name of young people as the 'next generation' or 'the future'.

Arguably, the study of children and young people as social actors still needs to be mainstreamed into development thinking. Research is needed that addresses the temporally variable pathways of individuals, to capture the complexities of social lives. This is also crucial for theory building related to the life-course, showing the intersections between structural factors and individual lives over time, and which has great potential within development studies (see Locke \& Lloyd-Sherlock, 2011). Finally, policies related to children and young people tend to be segmented by age and developmental stages, and children are dealt with in social policy silos - health, education, and so on. Links between differing aspects of their lives are not well-understood, nor seen holistically. QLR allows exploration of the cumulative experience of discrete policies on young people's trajectories 
(the long view rather than the short view) and how such policies may fail to meet children's and young people's needs across the life course.

\section{Young Lives: how is QLR used?}

Young Lives is a longitudinal study investigating childhood poverty in Ethiopia, Peru, India (Andhra Pradesh) and Vietnam over 15 years (2002-2017). The study aims to improve understanding of the causes and consequences of childhood poverty and the role of policies in improving children's life chances. It collects data from two cohorts of children in each country: 2,000 children born in 2000-1 (the younger cohort) and 1,000 children born in 1994-5 (the older cohort). A survey is carried out every three years $(2002,2006,2009,2013$, 2016) with all children and caregivers, and is complemented by QLR (2007, 2008, 2010, 2014 ) in 3 to 5 communities in each country, involving over 200 children, their caregivers, and other key figures.

Young Lives was not designed as a qualitative study, but five years in, to take advantage of the long-term design, a qualitative dimension was introduced to complement the survey, and to maximise Young Lives potential to explore temporality (see Crivello et al., 2013). From this a qualitative longitudinal approach emerged, and has become embedded within Young Lives, enabling us to capture shifts in biography over time. A range of methods are used to gather children's and caregivers' descriptions of everyday life, reflections on their childhoods (past, present and future); their views about what has contributed to shaping their well-being and their aspirations, focusing particularly on transitions. Analysis of qualitative data complements, and is often combined with, survey analysis; it focuses on factors explaining diverging experiences and trajectories, and analys is from survey and qualitative data has been vital for policy and communications purposes, adding richness and depth (cf. Elliott 2014). This has particular benefits in development studies, enabling us to challenge dominant assumptions about children as passive recipients of social change, by exploring how children actively navigate their way through childhood.

There are multiple layers of QLR and differing ways of exploring the dynamics of childhood poverty, including analysis at biographical, household, generational and community levels. For example, at the third round of qualitative research, we developed a line of enquiry relating to intergenerational time, by collecting life histories with parents/caregivers of children, asking them to reflect on how their childhood experiences compare to their children's. A key aim is to link individual biographies to trends in communities/countries, 
and how these change over time, in ways that one-off visits cannot. This enhances understanding of how children and their families respond to their changing environments and circumstances and what this means for children's trajectories. The two-cohort design and the timing of data collection also mean that we can compare experiences of the older and younger cohorts at similar ages. The four-country design enables better understanding of the apparent failure of economic growth to ameliorate poverty in three countries now categorised as 'middle-income' (Peru, India and Vietnam), as well as enabling a focus on patterns of relationships, and how the patterns are similar, in relation to the long term effects of poverty, the intergenerational transmission of poverty, and the unequal outcomes of development for children and young people - essential for theory-building. We can track the effects of social policies over time, for example, relating to the consequences of increased enrolment in school (in all four countries), the impacts of policies relating to early marriage (in Ethiopia and India), policies relating to child labour (all four countries) and the implications of a multiplicity of social protection schemes (Boyden \& James 2014). The themes developed in the qualitative research - relating to well-being, transitions/trajectories, and experiences of services (school, health and so on) - enable cross-national consistency in lines of enquiry and analysis.

Further, there are practical benefits to having a longitudinal element to the qualitative research. Research teams have been able to enhance their skills at each round, build up supportive relationships within teams and with research participants, in countries where there has not been a strong tradition of qualitative research with children. We try to employ the same field researchers who return to the same families, which builds trust and rapport, thus benefiting the wider study. We find examples of children talking about sensitive matters, such as the long term effects of family or domestic violence, which gives rise to reflection on the ethics of long-term research with children and families in difficult circumstances (Morrow, 2013b).

Young Lives research-to-policy engagement also incorporates elements of QLR design. For example, in Ethiopia, between 2009 and 2014, Young Lives developed a longitudinal consultative methodology involving diverse stakeholders working in child protection focusing on two areas of policy concern: 'orphans and vulnerable children' and 'children's work/labour' (Crivello \& Murray, 2012). A first phase involved semi-structured interviews with twenty researchers, practitioners and policy actors to explore aspects of research production and use by individuals and their organisations. The interviews were then analysed 
in terms of: research gaps and priorities, the types of research evidence used, and barriers to using research for policy and practice. Findings from the first phase were then used in two ways: a) to identify individuals and organisations who would participate as part of a consultation group that met at the beginning and end of the research-to-policy programme, and b) to inform a qualitative sub-study carried out midway through the programme on a priority research question agreed by the consultation group. Following analysis of data, the consultation group reconvened to discuss findings and to identify practical ways for breaking down barriers between research, policy and practice in relation to child protection. This highlights the way qualitative approaches can be combined with long-term research and policy engagement for particular outcomes (in this case, strengthening the linkages between research and policy and practice in Ethiopia) ${ }^{5}$. QLR here involved early and ongoing consultation, discussion of 'relevance' of research, and communicating to keep policymakers and practitioners engaged throughout the process (Crivello \& Murray, 2012).

\section{Examples of QLR: Tracing biographies, households and movements across time in Young Lives}

We turn to three examples that demonstrate differing dimensions of QLR. The final section discusses these, and highlights some challenges.

\section{Example 1: Trajectories to 'early marriage' in Ethiopia- a biographical view}

Repeat interviews with children explore their subjective experiences and explanations for their actions, decisions and trajectories as they unfold over time. Here, a case drawing on data collected in Ethiopia with a young woman, Haymanot ${ }^{6}$, illustrates a QL approach to children's biographies as shaped by family circumstances and by poverty.

Haymanot (born around 1994) is from Zeytuni, a remote community in Tigray region. People earn their living through farming, subsidised by petty trading, and wage work. Students who finish primary school have to travel to towns if they wish to continue studying. Haymanot was interviewed in 2007, 2008, 2011 and 20147. Three themes - food scarcity, ill-health, and the difficulties of trying to combine work and school - stand out as consistent threads running through her descriptions and relate to her marriage. A cross-sectional approach/survey would not have been able to explore Haymanot's agency, nor explain how her situation affected decisions.

In 2007, at age 11, Haymanot participated in a body-mapping ${ }^{8}$ group activity to explore children's well-being/ill-being. Haymanot described how she had been very ill with yellow 
fever. She also suffered from malaria, which worsened when she was working hard. Her education was affected by illness, because she missed so many classes. She had stayed with her aunt in another region, and got access to medicine, and she liked that her aunt provided her with soft drinks and better food. Haymanot had moved back the previous year to live with her mother who was ill (with heart disease) and there was no one else to care for her; Haymanot's father was absent. By 2008, Haymanot was despondent and worried, but eager to discuss her situation. She had briefly attended school in the afternoons because she was working in the mornings, but at the time of interview, was no longer at school. She was disappointed that she had so much responsibility at home and at work. She explained: 'my mother used to bake injera and fetch water. Now I am doing that.... I wash clothes and fetch firewood. I used to fetch water and currently I have to do that every day.'

Her mother reflected (in 2011) how Haymanot had gained a reputation for working hard, saying, 'Some people who saw her always working admired her and asked how she managed to work and withstand the hardship at this age'. Haymanot had worked crushing stones for two months, and was doing embroidery work at home. There had been drought and food shortage, and Haymanot's family had sold their livestock to stay afloat: 'We sold [the two cows] and covered the house with an iron sheet and spent the money on food'. The family could no longer afford labourers, so they began sharing their land with two other families and got half the yield. The quality of their food had declined as had the number of meals per day they ate, and they were now eating once a day:

'...we don't have much food at home and we have to eat accordingly... [in the past] we had enough food... we used to eat bread and tea as breakfast, injera with wot (stew) as lunch, supper after school and then dinner.'

Food was a major worry, and Haymanot and her sister alternated working shifts in the government food-for-work programme, which involved 'watering trees, digging the ground, building fences with stones', for which they were paid 10kg of wheat per month. But Haymanot missed school, and worried: 'I cannot have a job if I do not go to school'. She said 'I will be happy if I continue going to school and if my mother gets better'. She planned to marry when she was ' 20 to 25 ', though she explained that girls got engaged from the age of 12 , and married from the age of 13.

By 2010, aged 15, Haymanot was married to a man with whom she had a good acquaintance, and her wedding was arranged by her family. The researchers noted that she looked well, and was living in a good house. She said 'I am happy about my marriage because it was arranged 
by my family and I stopped doing paid work since marriage'. The previous three years had been hard because she had given up her job to look after her mother, who was still ill. She said that marriage was the best thing that happened to her within the past year. When asked if her marriage was due to poverty, she replied 'I don't think so'. But she did not want to marry at the age she did, and explained, 'it is because I don't go to school and I want to get some rest from the work'. When asked what her life would look like in three years' time, she said 'I think I will be at home doing household chores, perhaps having a child... because my husband wants a child'.

By 2014, Haymanot had a baby, but she was divorced, and she had returned to live with her mother (Pankhurst, 2014). Her mother believed Haymanot was abandoned by her husband because Haymanot's family were unable to provide a satisfactory dowry because they were so poor. Haymanot's husband has since remarried, to a woman from a wealthier family. Haymanot planned to work, and raise her child.

\section{Example 2: Poverty mobility - tracking households in India and Ethiopia}

Our second example uses QLR to trace the household as a unit of analysis. The study of household poverty dynamics lends itself to a mixed method approach, drawing on linked (panel) survey and (longitudinal) qualitative datasets. For example, Vennam and Andharia (2012) explored household poverty trends for the full sample in Andhra Pradesh across three survey rounds, noting that many households had experienced upward mobility during the seven-year period. They observed, however, that households located in tribal areas did not conform to this trend, and were more likely either to have stayed the same or to have experienced downward mobility. The sample participating in qualitative research mirrored this pattern, in that the households reporting downward mobility tended to have similar characteristics: they were more likely to be Scheduled Tribe ${ }^{9}$ households, to be early in their family life cycle, that is, with young children, to have started family life with debts (rather than with endowments) and to have experienced health and economic shocks. Case-level analysis of three rounds of qualitative data gathered from three tribal households illustrate the structural factors influencing their further descent into poverty, the actions and agency of household members, and consequences for children's wellbeing. For example, analysis of data from Krishna and his mother demonstrate an accumulation of economic and psychological distress brought on by a combination of factors related to poverty, familial death, the father's alcoholism, increasing debt and lack of social support. When interviewed 
in 2010, Krishna described how his father 'just buys alcohol, he does not buy us clothes'. Krishna's mother (2008) explained that despite earning a small amount, over time, the household circumstances deteriorated. In 2010, she despaired, saying: 'if there is no one to earn in the house, then what will happen?... how will we develop?'. The household had few assets to begin with, and so were unable to cope when faced with crisis, and the state offered little support (Vennam \& Andharia, 2012, p. 16). The authors conclude that while one set of policies may promote escape from poverty, further policies are needed to protect households from falling back into poverty.

Tafere (2014) explores poverty dynamics in Ethiopia, and how children fare in comparison to their households over time. Using household survey data, four possible poverty trajectories were identified: 'remained poor', 'moved into poverty', 'remained non-poor' and 'moved out of poverty', and six households spanning these categories were identified from the qualitative sample for case-level analysis. The main sources of data were interviews with children and caregivers (including life history data), as well as timelines (generated separately with children and their caregivers) which enabled participants to describe major life events. For example, survey data indicated that Hadush's household were doing much better financially. His father explained in 2011:

Before three years, we had a drought. We had to sell three cattle to survive. Now, we are living well. We have enough food and livestock. We have now our house roofed with corrugated iron... We use fertilizers and animal manure to increase the productivity of our land. We obtained loans from the saving and credit scheme and we sold our oxen to pay back the loan. Then we purchased other oxen. I also do masonry and earn some money. We are now middle in wealth (Hadush's father, cited in Tafere, 2014, p. 9).

Children's work contributes to household survival, and their contributions increase over time. Hadush's descriptions of his work illustrate this. When interviewed in 2008, aged 13, he explained:

I usually herd the cattle. When there is someone to herd them, I work in a private irrigation field for a wage. I also work in the safety net program. My father orders me to do these things. ... I earned about Birr 300 to 400 from the works I do in two months. I give the money to my father. We purchased goats and sheep with the money. We also bought coffee, sugar and other consumer items.

By 2011, he described the improved family situation:

Since last year, we have grown different kinds of vegetables and we earned a good amount of money by selling them. I bought new shoes and also goats and sheep. I 
fattened the sheep and sold them for profit. ... I also sometimes unload trucks and get about Birr 50 per day. I used the money to buy goats for breeding ... for my family. I also used to work in the safety net program and get $10 \mathrm{~kg}$ of cereals monthly.

We built a corrugated iron roofed house last year. We bought radio and a bed. We purchase oxen, cultivate our lands and harvest a good amount of yield. We purchased a cow for reproduction and production of milk. As a result, I am happy. I like my job. ..... In festivals/holidays, I buy liquor and meat for my families. I also buy clothes and shoes for myself. (Cited in Tafere, 2014, p. 18)

Overall, Hadush felt 'our life has improved ... I have contributed a lot but my father has also made a big contribution. We work hard'. By 2011, the household had graduated from the government safety net program they had previously relied on, and they were no longer considered food insecure.

Thus, within their families, children play important roles in responding to chronic poverty and to household shocks (often from an early young age) through various types of work, including care-giving; and children's actions to support family welfare often contributed to overall household improvements. However, there was sometimes a contradiction between children's wellbeing and the welfare trajectories of their households, and improvements at household level often came at the cost of an individual child's wellbeing (Tafere, 2014). Such contradictions became apparent in the interaction of survey data (based on adult responses) and qualitative data, demonstrating the importance of attending to the experiences of children, which may differ from adults and from their households (Tafere, 2014).

Children's agency emerged through the qualitative research, but would have remained hidden if only survey data were included.

\section{Example 3: Tracing migration aspirations and child mobility - a relational view from Peru}

Our final example applies QLR to the study of children's mobility in Peru (Crivello, 2011, Crivello, forthcoming). Holland et al. (2004, p. 31) suggest that QLR potentially contributes to new theoretical development in relation to social and geographical mobility and to the spatial dimensions of childhood, including migration and transnationalism. Peru is fertile ground to explore this, as it has a long history of migration. Households report high levels of mobility, with around a third having moved between 2002 and 2009, mostly from rural areas (Cueto et al., 2011, p.10). Historically, livelihoods have depended on mobility to overcome socio-spatial and economic inequality and to create linkages between rural and urban locations. Children have been and continue to be part of these movements, on their own or as 
part of their households. The increased focus placed on education means that children in rural areas are often required to migrate for schooling (Boyden, 2013).

QLR deepens insights from the survey about children's movements across space and time. The survey cannot easily capture the complexity of children's movements (particularly when they move on their own, or when they move multiple times between survey rounds ${ }^{10}$ ). The biographical approach of QLR means that we can explore children's mobility and migration histories, leading to thematic analysis of migration-related questions. For example, when enquiring about motivations for migration, surveys often require a single response per question, whereas a qualitative approach accommodates flexibility, multiplicity and even contradiction. It can be difficult to identify one reason for children's relocation or to discern the extent to which children themselves influenced migration decisions. Elmer's case is illustrative (see Crivello, forthcoming). During primary school his family moved to a nearby ranch. Age twelve, he moved to Lima where his sister had migrated five years earlier. She sent for him so that he could look after her children while she and her husband worked. In exchange, she paid for Elmer's upkeep and schooling. The previous year, Elmer's brother (aged 17) had lived there for the same reason, but he returned to the village so that he could graduate with his friends. The following year, Elmer returned to the village, and his older brother, having graduated, returned to his sister's house so that he could pursue higher education in the capital. Their parents moved to a village where they had purchased a plot of land, and the children, including Elmer, stayed in a different village to attend school. Each weekend the children walked three hours to their parents' to help in the fields. The latest survey round (2013) found Elmer still living in the village, but by 2014, he had returned to his sister's house to pursue his studies. Although this example draws on a single case, crosscase analysis across multiple rounds of data enables the identification of trends in the qualitative sample. In this vein, QLR has examined the relationship between children's migration aspirations, their social networks and their migration outcomes over time.

\section{Discussion}

'Early marriage', 'chronic poverty' and 'migration' are all concerns for development policy. QLR has potential to inform the evidence base underpinning policies and interventions, to contribute to understandings of poverty dynamics and children's experiences of poverty, and to demonstrate how individual biographies take shape within the context of wider familial and social processes. A QLR approach means that children's descriptions of living in 
poverty are captured, and that they have a role in defining what poverty means to them and in identifying the changes in their lives over time. Longitudinal design captures flexibility in children's life courses, whether related to schooling, residence, aspirations or marriage, which are not experienced as linear processes.

In our first example, we sought to demonstrate how a qualitative longitudinal approach aims to produce more than a series of individual snapshots in time, since Haymanot's biography can only make sense with reference to her evolving family situation in the context of her community - food shortages caused by drought, ill-health of her mother, lack of sources of support, and chronic poverty. She knew that the ideal age to marry was '20 or 25', but her poverty meant that she and her family saw marriage as a way to solve some of their problems. Marrying enabled her to gain temporary respite from hard work, and to continue to help her mother. Haymanot acknowledged the importance of schooling for her future, but she found it difficult to balance schooling with her work. Work provided her with food, but was physically taxing. Ill-health was a consistent theme, yet formal health provision was not adequate to help her, nor to treat her mother until 2011 when the family were able to pay for treatment. Haymanot's biography, would, in international policy circles, probably be regarded as having a negative outcome, that is, early marriage and motherhood. She would probably be seen as needing to be 'empowered' to continue in school and get a job in an imagined labour market. But a reading of her circumstances over time highlights that early marriage was a strategy to address impoverished circumstances. The insights gained though QLR in this example are highly pertinent to development studies (and beyond), because they enable us to work with temporality in a way that illuminates process and complexity, and not simply discrete events over a period of time. The holistic and synchronised nature of QLR enables an understanding of the contingency of biography in a way that is obscured by variable-based approaches, and should ultimately generate differing kinds of theory-building that take seriously the interaction of factors in time.

In the second example, we showed how researchers have combined longitudinal panel and qualitative datasets to explore factors influencing households moving into and out of poverty in India and Ethiopia, and the consequences for children. The relationship between overall household welfare and individual children's well-being demonstrates the importance of incorporating children's accounts of their experiences. The contradictions between differing data sources highlights aspects of children's lives in ways that would have been missed in 
cross-sectional or quantitative research, such as dynamism/change over time and children's agency in responding to household poverty.

The third example focused on migration, widely recognized as an intrinsic part of development processes, and although the migration-development nexus is high on the global policy agenda, children's accounts of their experiences remain marginal to the debates. Development discourse focuses on the negative aspects of children's mobility, on the risks associated with independent child migration and on exploitative migration associated with child trafficking. Since Young Lives focuses on everyday experiences of poverty (not 'extreme' cases or categories), we analyse children's mobility within the context of their daily lives, their schooling, work and aspirations. QLR deepens understanding of the way migration decisions are made within the context of young people's relationships and networks, and in response to changing household circumstances and opportunity structures. The case of Elmer illustrated the need to understand migration in terms of flexibility and process, rather than as a one-off event experienced by individuals in isolation, and relates to the challenges of using a QL approach in a way that does more than produce a series of 'shapshots'. Building time into the design thus enables researchers to trace changing aspirations, expectations and actions related to migration, and how these are influenced by dynamic life course factors such as gender-age.

\section{Challenges}

The promises of QLR also come with practical and ethical considerations. First, generalisability is valued by development research audiences and policy-makers, but 'the variations and complexity in life trajectories and the lives to which they are linked pose serious challenges'(Locke and Lloyd-Sherlock, 2011, p. 1136-1137), which is why linking QLR to the survey is imperative. A second problem is how to avoid presenting a series of snapshots. Here, returning to the same individuals regularly means that we can capture the cumulative effects of adversity, and the strategies children and young people adopt to overcome them. QLR shows this in ways that survey data cannot, by exploring some of the dynamic processes that led to the outcomes. QLR goes beyond memory work or life-history interviewing because it captures how children feel in the moment. In doing so, we avoid the trap of interpreting the past through the present. For example, if we had not interviewed Haymanot at the particular moments that we did, we would never have captured her earlier ambitions to continue in school, marry later, and so on - all of these moments were points in time when policies could have intervened to produce differing, perhaps more satisfactory, 
outcomes. QLR enhances understandings of the durational aspects of poverty, as well everyday experiences of poverty over time, which has potential for making policy that contributes to alleviating it (Paerregaard, 1998).

Finally, there is the question of scepticism within development studies about qualitative research - credibility, bias, lack of possibility for scrutiny. Collaborative team working is a helpful counter to this - sharing and cross-checking analysis with research partners, as well as transparent documentation of methods, experiences, and lessons learned. However, disciplinary boundaries mean that we need to get beyond the level of thinking that qualitative research is about 'stories' (which implies something fictitious or capricious), to thinking about systematic integration of qualitative and survey analysis, iteratively, as we try to do in Young Lives.

In conclusion, in the cases presented here, we have emphasised the importance of time and temporality in understanding poverty trajectories, individual biographies, and migration across space and time. QLR in Young Lives over a decade presents an opportunity to explore how children's lives change in the light of their experiences, in four countries undergoing rapid social and economic development. This is unusual in development studies, a field dominated by rational choice theorisation. We hope that future research will continue to expand and develop QLR, as it enables new ways of thinking to emerge that capture the complexities of how social processes shape, constrain and enable individual biographies over time.

\section{References}

Bernays, S., Seeley, J., Rhodes, T.,\& Mupambireyi, Z. (forthcoming) 'What am I 'living' with?' Growing up with HIV in Uganda and Zimbabwe. Sociology of Health and Illness, doi: $10.1111 / 1467-9566.12189$

Boyden, J. (2013). 'We're not going to suffer like this in the mud": educational aspirations, social mobility and independent child migration among populations living in poverty. Compare, 43, 5, 580-600.

Boyden, J. \& James, Z. (2014). 'Schooling, childhood poverty and international development: choices and challenges in a longitudinal study', Oxford Review of Education 40, 1, 10-29.

Corden, A., \& Millar, J. (2007). Qualitative longitudinal research for social policy. Journal of Social Policy, 6, 4, 529-532. 
Crivello, G. (2011). Becoming somebody. Youth transitions through education and migration in Peru. Journal of Youth Studies 14, 4, 395-411.

Crivello, G. (forthcoming) "There's no future here": the time and place of young people's migration aspirations in Peru. Geoforum.

Crivello, G., Morrow, V., \& Wilson, E. (2013). Longitudinal Qualitative Research: a guide for researchers. Technical Note 26, Oxford: Young Lives.

Crivello, G. \& Murray, H. (2012) Why strengthening the linkages between research and practice is important. Policy Brief 19, Oxford: Young Lives.

Cueto, S., Escobal, J., Penny, M.,\& Ames, P. (2011) Tracking disparities: Who gets left behind? Oxford: Young Lives.

Davis, P., \& Baulch, B. (2011). Parallel realities: exploring poverty dynamics using mixed methods in rural Bangladesh. Journal of Development Studies, 47, 1, 118-142.

Dyson, J. (2014). Working Childhoods: Youth, Agency and the Environment in India, Cambridge: CUP.

Elliott, J. (2014). The power and perils of narrative: making the best use of the British Birth Cohort studies. Inaugural professorial lecture. London: Institute of Education.

Ennew, J., \& Milne, B. (1989). The next generation. Lives of third world children. London: Zed.

Fourcade, M., Ollion, E., \& Algan, Y. (2014). The superiority of economists. Discussion paper 14/3. Paris: Maxpo Centre.

Huijsmans, R., George, S., Gigengack, R. \& Evers, S. (2014). Theorising age and generation in development. European Journal of Development Research, 26, 2, 163-174.

Hulme, D. (2004). Thinking 'small' and the understanding of poverty: Maymana and Mifizul's story. Journal of Human Development, 5, 2, 161-176.

Hulme, D., \& Moore, K. (2010). Thinking small, and thinking big about poverty: Maymana and Mofizul's story updated. Bangladesh Development Studies, 33, 3, 69-96.

Katz, C. (2004). Growing Up Global: Economic Restructuring and Children's Everyday Lives. Minnesota: University of Minnesota Press

Lewis, D. (2009). International development and the 'perpetual present': anthropological approaches to the re-historicization of policy. European Journal of Development Research, 21, $1,32-46$.

Locke, C. \& Lloyd-Sherlock, P. (2011). Qualitative life course methodologies: critical reflections from development studies. Development and Change, 42, 5, p. 1131-1152.

McLeod, J., \& Thomson, R. (2009). Researching Social Change. London:Sage.

Morrow, V. (2013a). Troubling transitions? Young people's experiences of growing up in poverty in rural Andhra Pradesh, India. Journal of Youth Studies, 16, 1, 86-100 
Morrow, V. (2013b). Practical Ethics in Social Research with Children and Families in Young Lives. Methodological Innovations Online, 8, 2, 21-35.

Paerregaard, K. (1998). Intercepting local lives in a global world: the use of life histories in the research of poverty. In N Webster (ed) In search of alternatives: poverty, the poor and local organisations. Working Paper 98.1. Copenhagen: Centre for Development Research.

Pankhurst, A. (2014). Child marriage and female circumcision (FGM/C): Evidence from Ethiopia. Policy Brief 21, Oxford: Young Lives.

Punch, S. (2012). Studying transnational children: A multi-sited, longitudinal, ethnographic approach. Journal of Ethnic and Migration Studies, 38, 6, 1007-1023.

Ridge, T. \& Millar, J., (2011). Following families: working lone-mother families and their children. Social Policy \& Administration, 45, 1, 85-97.

Roelen, K. (2014). Using Qualitative And Panel Data To Create Durable Measures Of Child Poverty And Wellbeing Across Childhood. In L. Camfield (ed.) Methodological challenges and new approaches to research in international development. London: Palgrave Macmillan.

Roelen, K. \& Camfield, L. (2013). A Mixed-Method Taxonomy of Child Poverty - the Case of Ethiopia Applied Research in Quality of Life, 8, 3, 319-337.

Shaffer, P. (2013). Ten years of "Q-squared": implication for understanding and explaining poverty. World Development, 45, 269-285.

Tafere, Y. (2014). Children's experiences of household poverty dynamics in Ethiopia. Working paper 132, Oxford: Young Lives.

Thomson, R., Hadfield, L., Holland, J., Henwood, K., Moore, N., Stanley, L. \& Taylor, R. (2014). New frontiers in QLR: definition, design and display. Technical Report. NCRM. http://eprints.ncrm.ac.uk/3297/

Thomson, R.\& McLeod, J. (2015). Introduction to Special issue: New frontiers in qualitative longitudinal research. International Journal of Social Research Methodology.

UN (2013). A New Global Partnership: Eradicate Poverty and Transform Economies Through Sustainable Development. Report of the High-level Panel of Eminent Persons on the Post-2015 Development Agenda, New York: United Nations.

Van Blerk, L. \& Shand, W. (2014.) Growing up on the streets: research with and for young people on the street. Briefing Paper 2, London: Streetinvest.

Vennam, U., and Andhraria, J. (2012). Chronic Poverty Amid Growth: Insights from LongTerm Poverty Trajectories Working paper 84, Oxford: Young Lives.

White, S., and Jha, S. (2013) The politics of wellbeing conservation and development in Chiawa, Zambia. Wellbeing and Poverty Pathways Briefing No 2. Bath: University of Bath.

\section{Acknowledgements}


The authors thank the children, parents and others who participate in Young Lives, the research teams responsible for data-gathering. We are also very grateful to Paul Dornan, Kirrily Pells, Emma Wilson, two anonymous reviewers and guest editors, audiences at the Child in Time Conference at University of Sussex (2013) and Development Studies Association conference (2013) for their encouragement and helpful comments on earlier versions of this paper.

\footnotetext{
${ }^{1}$ A search of World Development, for example, shows a small number of papers that use qualitative data, nearly always in conjunction with survey findings, in mixed methods papers.

${ }^{2}$ See Davis \& Baulch, 2011, Roelen, 2014, Camfield \& Roelen, 2014, Shaffer, 2013, on mixed methods.

${ }^{3}$ See Corden and Millar 2007 for a review.

${ }^{4}$ Qualitative research with children and young people in low and middle-income countries tends to be published in youth studies or childhood journals like Childhood, Children's Geographies, Children \& Society, Journal of Youth Studies and Children and Youth Environments. For a recent exception see Huijsmans et al. (2014) special is sue of European Journal of Development Research.
}

${ }^{5}$ This led to the establishment of the Child Research and Practice Forum (CRPF) which, since 2010, meets monthly for researchers, practitioners and policy makers to share current research, to build local capacity for using research, and to shape future research agendas.

${ }^{6}$ All names are pseudonyms.

${ }^{7}$ At the time of writing, data gathered in 2014 were not available for analysis, though we include some information from the research team.

${ }^{8}$ A visual method using a large sheet of paper with the outline of a body that enables children to mark and describe how they felt/feel, and what made them felt/feel better.

${ }^{9}$ Scheduled Tribes are indigenous communities who are traditionally disadvantaged, and live in forests and mountainous areas.

${ }^{10}$ The third round of the survey (2009) included questions about migration aspirations, where children had migrated, reasons why they moved and how they rated their current situation compared to their life prior to migration. 